\title{
Impacts of Fintech to Finance-Banking activities and recommendation for Finance-Banking industry in Vietnam
}

\author{
Huong Thu Pham *, Tuan Anh Dao
}

Faculty of Economics and Business Administration, Hanoi University of Mining and Geology, Vietnam

\begin{tabular}{ll} 
ARTICLE INFO & ABSTRACT \\
\hline $\begin{array}{l}\text { Article history: } \\
\text { Received 18th Aug. 2020 } \\
\text { Revised 03rd Sept. 2020 } \\
\text { Accepted 31st Oct.2020 }\end{array}$ & $\begin{array}{l}\text { Impact of the 4th industrial revolution on development of finance and } \\
\text { banking system (TCNH) is increasingly clear with the launch of a series of } \\
\text { new and innovative banking products and services, as well asintroduction } \\
\text { of new distribution channels for banking services based on financial } \\
\text { technology platform (Fintech). On the basis of components and products }\end{array}$ \\
$\begin{array}{l}\text { Keywords: } \\
\text { Fintech, }\end{array}$ & $\begin{array}{l}\text { of Fintech ecosystem, the article mentioned Fintech market in Vietnam, } \\
\text { clarifying positive and negative impacts of Fintech on operations of } \\
\text { finance-banking industry, from there to issue some recommendations for } \\
\text { activities of Vietnam's Finance-Banking industry to meet new trends. }\end{array}$
\end{tabular}

Copyright @ 2020 Hanoi University of Mining and Geology. All rights reserved.

${ }^{*}$ Corresponding author

E-mail: phamthuhuong@gmail.com

DOI: 10.46326/ JMES.KTQT2020.14 


\title{
Tạp chí Khoa học Kỹ thuật Mỏ - Địa chất
}

\section{Tác động của Fintech tới hoạt động Tài chính - Ngân hàng và khuyến nghị cho ngành Tài chính - Ngân hàng Việt Nam}

\author{
Phạm Thu Hương*, Đào Anh Tuấn \\ Khoa Kinh tế và Quản trị kinh doanh, Trường Đại học Mỏ - Địa chất, Việt Nam
}

\section{THÔNGTINBÀI BÁO TÓMTẮT}

\section{Quá trình:}

Nhận bài 18/8/2020

Sửa xong $3 / 9 / 2020$

Chấp nhận đăng 31/ 10/ 2020

Tù khóa:

Fintech,

Tài chính - ngân hàng.
Tác động của cách mạng công nghiệp lần thư 4 đến sự phát triển của hệ thống tài chính - ngân hàng (TCNH) ngày càng rõ nét với việc xuất hiện của hàng loạt các sản phẩm, dịch vụ ngân hàng đổi mói sáng tạo, cũng như sự ra đời các kênh phân phối dịch vụ ngân hàng mói dưa trên nền tảng công nghê tài chính (Fintech). Trên cơ sở các thành phần vá sản phẩm của hê sinh thái Fintech, bài báo đâ đề cập đến thị trường Fintech tại Viêt Nam, lăm rõ nhưng tác động tích cực và tiêu cực của Fintech tới hoạt động của ngành $\mathrm{TCNH}$, tù đó đề xuất một số khuyến nghi đối với hoạt động của ngành TCNH Việt Nam để đáp úng các xu hướng mói.

(c) 2020 Trường Đại học Mỏ - Địa chất. Tất cả các quyền được bảo đảm.

\section{Mở đầu}

Cách mạng công nghiệp 4.0 diễn ra mạnh mẽ và tạo ra những biến chuyển trên nhiều lĩnh vực xã hội. Đối với lĩnh vực tài chính - ngân hàng, cách mạng công nghiệp 4.0 tác động rõ rệt, thể hiện ở sự xuất hiện của FinTech - công nghệ tài chính. Fintech được xem là tín hiệu dẫn đầu cuộc cách mạng 4.0, mang đến cho con người nhiều tiện ích thông qua sự phát triển công nghệ toàn diện. Các ưng dụng đa dạng của Fintech đang tác động đến hầu hết mọi lĩnh vực hoạt động của ngành tài chính như tiền gửi, thanh toán, bảo hiểm, chứng khoán, tín dụng, quản trị rủi ro, cơ cấu thị trường, cơ cấu sản phẩm, chiến lược phát triển của cả hệ thống tài chính ngân hàng.

\section{*Tác giả liên hệ}

E - mail: phamthuhuong@gmail.com

DOI: 10.46326/ JMES.KTQT2020.14
FinTech đã và đang làm thay đổi cách thức, địa điểm và thời gian người tiêu dùng thực hiện thanh toán, cũng như tạo thuận lợi để người tiêu dùng có thể tiếp cận tới nhiều loại hình dịch vụ tài chính, góp phần thu hẹp khoảng cách giữa các tầng lớp xã hội. Với Fintech, nhiều mô hình và sản phẩm tài chính số hóa đã xuất hiện như ví điện tử, chuyển tiền ngang hàng, thanh toán di động, ngân hàng di động, cho vay ngang hàng, huy động vốn cộng đồng, ngân hàng chuỗi khối, ngân hàng số,... đã làm thay đổi mạnh mẽ phương thức hoạt động của các lĩnh vực tài chính - ngân hàng.

\section{Khái niệm và các thành phần, sản phẩm của FinTech}

\subsection{Khái niệm về FinTech}

Cho đến nay chưa có một định nghĩa thống nhất trên toàn cầu cho thuật ngũ "FinTech". Tuy nhiên"FinTech" là dạng viết tắt của cụm từ 
"financial technology" (công nghệ tài chính), thường biểu thị các công ty hoặc đại diện các công ty kết hợp các dịch vụ tài chính với các công nghệ hiện đại, sáng tạo. Như một quy ước, nhưng công ty mới gia nhập vào thị trường sẽ cung cấp các sản phẩm dựa trên Internet theo hướng ứng dụng. Các công ty FinTech thường hướng tới thu hút khách hàng bằng các sản phẩm và dịch vụ thân thiện với người dùng, hiệu quả hơn, minh bạch hơn và tự động hơn so với những sản phẩm và dịch vụ đã có. Ngoài cung cấp các sản phẩm và dịch vụ trong lĩnh vực ngân hàng, FinTech còn phân phối bảo hiểm và các công cụ tài chính khác hoặc cung cấp các dịch vụ bên thứ ba.

Theo FSB (2019), FinTech là các sáng tạo trong tài chính dựa trên nền tảng công nghệ nhằm tạo ra các mô hình kinh doanh, ứng dụng, quy trình, hay sản phẩm mới có tác động cụ thể đến các thị trường và định chế tài chính, cũng như các dịch vụ tài chính.

Do đó có thể hiểu FinTech là việc áp dụng các công nghệ đổi mới, sáng tạo và hiện đại vào lĩnh vực tài chính - ngân hàng nhằm mang tới cho khách hàng các dịch vụ tài chính minh bạch, hiệu quả và thuận tiện với chi phí thấp hơn so với các dịch vụ tài chính truyền thống.

Theo (Anjan, 2020), một số dịch vụ FinTech thường cung cấp như thanh toán, cho vay, chuyển tiền, Fintech; gọi vốn cộng đồng (crowd-funding), cho vay ngang cấp (peer to peer lending), tư vấn tài chính cá nhân (Personal Finance), công nghệ bảo hiểm (Insur-Tech), tiền tệ số (Crypto Blockchain), quản trị dũ liệu (Data Management),...

\subsection{Các thành phần và sản phẩm của FinTech}

Theo In Lee, Yong Jae Shin (2018), hệ sinh thái Fintech gồm có 5 thành phần cơ bản: (1) Các công ty khởi nghiệp dịch vụ tài chính (fintech startups) (ví dụ trong các mảng thanh toán, quản lý tài sản, cho vay, huy động vốn từ cộng đồng, thị trường vốn và các công ty bảo hiểm); (2) Các nhà phát triển công nghệ (technology developers) (ví dụ: phân tích dữ liệu lớn, điện toán đám mây, tiền ảo, mạng xã hội,...); (3) Chính phủ (ví dụ, cơ quan quản lý tài chính và lập pháp); (4) Khách hàng dịch vụ tài chính (cá nhân và tổ chức), và (5) Các tổ chức tài chính truyền thống (ví dụ, ngân hàng truyền thống, công ty bảo hiểm, chứng khoán, và các công ty môi giới và các nhà đầu tư mạo hiểm).
Các sản phẩm trong Fintech thường được chia thành 2 nhóm phân theo đối tượng sử dụng (In Lee, 2018); (Milian, 2019).

Nhóm thứ nhất: các sản phẩm phục vụ người tiêu dùng, các công cụ kỹ thuật số và công nghệ khác để cải thiện cách các cá nhân vay mượn, quản lý tiền bạc, tài trợ vốn cho các startup.

Nhóm thứ hai: các sản phẩm công nghệ "backoffice" nhằm hỗ trợ cho hoạt động của các Fintech và các định chế tài chính.

Một số sản phẩm nổi bật nhất của Fintech trong lĩnh vực TCNH có thể kể đến như (Anjan, 2020); (Lee và Shin, 2018).

* Các loại ví điện tữ:

Ví điện tử là một loại tài khoản điện tử, nó đóng vai trò là phương tiện thanh toán trực tuyến dành cho khách hàng, giúp khách hàng thanh toán các loại chi phí, gửi tiền và nhận tiền qua Internet một cách nhanh chóng.

Ví điện tử ra đời từ những năm 1990 nhằm giúp người tiêu dùng lưu trữ thông tin cá nhân và mua bán hàng hóa nhanh chóng, dễ dàng qua mạng internet. Cùng với sự phổ biến của điện thoại di động, những năm gần đây lượng người sử dụng Ví điện tử tăng lên nhanh chóng.

* Bitcoin - đồng tiền điện tử

Nhắc tới sản phẩm Fintech, không thể không nhắc tới Bitcoin. Có thể nói, Bitcoin là một trong những từ khóa 'hot' nhất trong ngành tài chính hiện nay.

Bitcoin là một loại tiền tệ kỹ thuật số phân cấp, được phát hành bởi Satoshi Nakamoto dưới dạng phần mềm mã nguồn mở từ năm 2009. Bitcoin có thể được trao đổi trực tiếp bằng thiết bị kết nối Internet mà không cần thông qua một tổ chức tài chính trung gian nào.

Bitcoin có cách hoạt động khác hẳn so với các loại tiền tệ điển hình: Không có một ngân hàng trung ương nào quản lý nó và hệ thống hoạt động dựa trên một giao thức mạng ngang hàng trên Internet.

Người ta cũng lập ra nhiều sàn giao dịch để những người không đào được có thể mua bán Bitcoin. Nguồn cung Bitcoin cũng được giới hạn ở mức tổng cộng là 21 triệu đồng Bitcoin.

* Kickstarter - Gọi vốn cộng đồng

Gọi vốn cộng đồng cũng là một sản phẩm điển hình của Fintech. Có rất nhiều ứng dụng gọi vốn cộng đồng khác nhau tùy theo mục đích hay cách 
thức gọi vốn, mà Kickstarter là một trong những ưng dụng tiêu biểu nhất.

Kickstarter được tạo ra vào năm 2009 tại New York, cho phép các nhà phát triển, kinh doanh, sáng tạo có khả năng đem dự án của mình ra huy động vốn từ những người tiêu dùng thông thường trên mạng internet. Là một trong những trang đầu tiên giúp huy động vốn từ cộng đồng, Kickstarter đã giúp cho việc gọi vốn của các startup trở nên dễ dàng và đơn giản hơn rất nhiều.

\section{Thị trường Fintech tại Việt Nam}

Theo (Solidiance ,2018), thị trường Fintech Việt Nam trị giá 4,4 tỷ USD tính tới năm 2017 và được dự đoán sẽ đạt 7,8 tỷ USD vào năm 2020, tương đương với mức tăng $77 \%$ trong vòng ba năm. Sự phát triển của Fintech tại Việt Nam đang tăng trưởng mạnh mẽ, thu hút 117 triệu USD vốn khởi nghiệp, vượt qua thị trường E-commerce đang ở mức 104 triệu USD và các lĩnh vực khác khiến Fintech trở thành lĩnh vực được tài trợ nhiều nhất cho giới khởi nghiệp năm 2018.

Theo United Overseas Bank, Singapore FinTech Association (2019), tính đến ngày 30 tháng 9 năm 2019, Việt Nam đứng thứ hai trong khu vực ASEAN về số vốn được tài trợ cho thị trường Fintech, thu hút 36\% đầu tư của khu vực vào năm 2019, chỉ đứng sau Singapore (51\%).

Fintech tại Việt Nam chủ yếu tập trung vào phân khúc thanh toán với $47 \%$ công ty trền thị trường làm về dịch vụ thanh toán, chiếm tỷ lệ cao nhất trong khu vực. Phân khúc thanh toán thu hút được nhiều nhà đầu tư là quy luật chung của các nước có thị trường Fintech phát triển ở giai đoạn đầu. Các công ty trong phân khúc này đã chiếm 98\% tổng số tiền tài trợ cho thị trường Fintech tại Việt Nam vào năm 2019. Hiện có 35 startup và nền tảng trên thị trường, đứng đầu là MoMo sau đó đến VNPay $Q R$, VinID Pay và một số nền tảng khác nhu: ZaloPay, GrabPay by Moca, Airpay (Nguyễn Trung Anh, 2019; Phạm Xuân Hòe, 2019).

Ngoài ra còn có một số dịch vụ Fintech khác nhu:

* P2P lending (peer-to-peer lending)

P2P lending hay cho vay ngang hàng cho phép các cá nhân và doanh nghiệp cho nhau vay và mượn tiền. Với cấu trúc hiệu quả, các công ty Fintech cho vay P2P có thể đưa ra mức lãi suất thấp và cải thiện quy trình cho vay giữa người cho và người vay. Một khác biệt nhỏ nhưng cũng quan trọng so với một ngân hàng là những fintech này về mặt kỹ thuật không liên quan đến việc cho vay, mà chỉ đơn giản là kết nối giữa người cho vay với người cần vay và thu phí của người dùng. Đây là phân khúc Fintech lớn thứ hai tại Việt Nam với hơn 20 công ty khởi nghiệp. Những công ty nổi bật trong phân khúc này bao gồm:

Tima: công ty tài chính tiêu dùng và nền tảng cho vay ngang hàng ( $\mathrm{P} 2 \mathrm{P}$ lending). Công ty này đã ký kết hợp tác với các tổ chức tài chính như ngân hàng Vietinbank và ngân hàng Đông Á, và tuyên bố đã giải ngân khoảng 1,7 tỷ USD khoản vay cho 2,8 triệu người và có hơn 30.000 người cho vay trên nền tảng của mình. Tima tuyên bố đã huy động được vòng gọi vốn Series $B$ trị giá 3 triệu USD vào tháng 10 với mức định giá gần 20 triệu USD và gần đây đã bắt đầu quá trình huy động vòng gọi vốn Series C. (Nguyễn Trung Anh, 2019; Phạm Xuân Hòe, 2019).

Vay Muon: Công ty Cổ phần Vay Mượn Vaymuon.vn lần đầu ra mắt vào cuối năm 2017. Đến nay VayMuon.vn là một trong những nền tảng cho vay ngang hàng (peer-to-peer lending platform) hàng đầu tại Việt Nam, kết nối hơn 2 triệu lượt khách hàng với gần 400 nghìn nhà đầu tư và tăng trưởng trên $20 \%$ mỗi tháng. Vaymuon.vn đã nhận vốn đầu tư hạt giống đến từ tập đoàn NextTech, nhà đầu tư chiến lược hiện đang chiếm 20\% cổ phần startup. Năm 2019 công ty gọi vốn Series A từ 5 đến 10 triệu USD để tiến ra thị trường nước ngoài, (Nguyễn Trung Anh, 2019; Phạm Xuân Hòe, 2019).

* Ngân hàng số (digital banking)

Digital Banking hay ngân hàng số là ngân hàng có thể thực hiện hầu hết các giao dịch ngân hàng bằng hình thức trực tuyến thông qua Internet. Giao dịch của ngân hàng số không phải đến chi nhánh ngân hàng và giảm thiểu đến mức tối đa những thủ tục giấy tờ liên quan. Đồng thời tính năng của ngẩn hàng số có thể thực hiện mọi lúc mọi nơi không phụ thuộc vào thời gian, không gian nên khách hàng hoàn toàn chủ động. Phân khúc này có 5 công ty khởi nghiệp, nổi bật làTimo: Ngân hàng kỹ thuật số được phát triển trên nền tảng sử dụng đường truyền internet để hoạt động thông qua 2 kênh là ứng dụng Mobile Banking và Internet Banking. Timo được đảm bảo và đồng phát triển bởi ngân hàng VPBank. Mới đây, Timo đã chuyển đối tác sang ngân hàng Bảo Việt (Nguyễn Trung Anh, 2019; Phạm Xuân Hòe, 2019) 
* Blockchain/ Crypto

Phân khúc Blockchain/ Crypto với 17 startup. Đây là một lĩnh vực khác đã chứng kiến các giao dịch đáng kể trong những năm gần đây. Kể từ khi Bitcoin Việt Nam ra mắt vào năm 2014, một số công ty đã nổi lên để tham gia vào blockchain và tiền điện tử. Các công ty đáng chú ý bao gồm:

TomoChain: một giải pháp sáng tạo cho vấn đề mở rộng của Ethereum blockchain cũng như những nền tảng blockchain hiện tại. Công ty khởi nghiệp này đã huy động được 8,5 triệu USD trong đợt chào bán tiền xu ban đầu (ICO) vào năm ngoái và được hỗ trợ bởi một số công ty đầu tư nổi tiếng như Signum Capital, Connect Capital và $1 \mathrm{KX}$, (Nguyễn Trung Anh, 2019; Phạm Xuân Hòe, 2019).

Kyber Network (KNC): một nền tảng giao dịch phân cấp mới đáng tin cậy, cho phép giao dịch gần như ngay lập tức và chuyển đổi giữa bất kỳ tài sản kỹ thuật số nào với nhau. Kyber Network bắt đầu tiến hành ICO vào ngày 22/9/2017 tại Singapore, chỉ sau vài giờ đồng hồ dự án này đã huy động được 200.000 ETH tương đương với khoảng 52 triệu USD (khoảng 1.200 tỷ VNĐ), biến Kyber Network trở thành thương vụ gọi vốn lớn nhất trong lịch sử startup của Việt Nam và ngang hàng với 10 công ty khởi nghiệp hàng đầu thế giới về số tiền được huy động năm 2017, (Nguyễn Trung Anh, 2019; Pham Xuân Hòe, 2019).

\section{Tác động của Fintech tới hoạt động tài chính - ngân hàng}

\subsection{Các tác động tích cực}

FinTech làm thay đổi kênh phân phối và các sản phẩm dịch vụ tài chính truyền thống.

Làm thay đổi kênh phân phối sản phẩm truyền thống là tác động nổi bật và rõ ràng nhất của Fintech. Đặc biệt là dịch vụ ngân hàng. Sự thay đổi kênh phân phối này có bước đột phá khi hàng loạt các kênh bán hàng ra đời thông qua internet như Mobile Banking,mạng xã hội, phát triển ngân hàng kỹ thuật số, giao dịch không giấy tờ...Fintech đã làm thay đổi rõ rệt phương thức giao dịch lẫn phân phối cũ trước đây ở ngành tài chính ngân hàng.

FinTechcung cấp đa dạng dịch vụ cho người dùng.

Ngoài nhưng dịch vụ thông thường như thanh toán, cho vay, chuyển tiền, Fintech còn cung cấp các dịch vụ trải rộng hơn như gọi vốn cộng đồng, cho vay ngang cấp, tư vấn tài chính cá nhân, công nghệ bảo hiểm, tiền tệ số quản trị dữ liệu,... Sự đa dạng dịch vụ của Fintech đáp ứng nhiều nhu cầu của khách hàng hiện nay.

Thu thập dữ liệu lớn.

Fintech với các ứng dụng công nghệ cao có thể giúp thu thập và phân tích lượng lớn dữ liệu khách hàng. Thông qua việc thu thập big data, nhưng người làm ngân hàng tài chính có thể tiết giảm chi phí nhân sự, tìm hiểu kĩ lưỡng khách hàng của mình. Đồng thời hỗ trợ căn cứ cho việc thực hiện các quyết định nâng cao chất lượng dịch vụ tiến tới sự hài lòng cho khách hàng sử dụng các dịch vụ trong lĩnh vực tài chính ngân hàng.

Các hoạt động tài chính ngân hàng diễn ra nhanh và tiết kiệm.

Ứng dụng cồng nghệ của Fintech có thể làm thay đổi toàn bộ cơ cấu thị trường, cơ cấu sản phẩm bằng máy móc, tối giản hóa lao động sức người. Xu hướng "ngân hàng không giấy", "tổ chức tài chính không giấy" giúp các giao dịch tài chính, hoạt động diễn ra trong ngân hàng diễn ra nhanh chóng, minh bạch và tiết kiệm. Ngoài ra, nó còn đảm bảo được sự an toàn, giảm thiểu rủi ro cho khách hàng khi sử dụng hay đầu tư vào ngành tài chính ngân hàng.

Tạo nên sức cạnh tranh nhờ ưu thế công nghệ.

Các ngân hàng, công ty tài chính ngày nay phải cạnh tranh gay gắt để giành lấy khách hàng cho mình. Fintech là chì khóa tạo nên thế cạnh tranh giữa các công ty ngân hàng thêm quyết liệt. Đơn vị dẫn đầu về ứng dụng công nghệ Fintech sẽ gặt hái được thành công và lợi nhuận nhiều hơn so với việc chậm nhịp với công nghệ. Điều này được minh chứng bởi những ngân hàng trẻ mới ra đời đủ sức vươn lên cạnh tranh với ông lớn bằng ưu thế công nghệ Fintech.

\subsection{Các tác động tiêu cực}

Ngoài những tác động tích cực, Fintech cũng được đánh giá tiềm ẩn một số rủi ro. Làn sóng công nghệ có thểhay thế phương thức truyền thống, công việc kinh doanh của nhiều ngân hàng, công ty tài chính sẽ gặp khó khăn hơn nếu họ không bắt kịp được với công nghệ.

Khách hàng bối rối.

Fintech ra đời với quá nhiều loại hình dịch vụ tài chính, dịch vụ. Điều này khiến khách hàng gặp khó khăn trong việc tìm hiểu về các dịch vụ, khó nắm bắt quyền lợi và nghĩa vụ của bản thân khi 
tham gia. Một số khách hàng cũng khó tiếp cận được các dịch vụ tài chính nếu thu nhập thấp.

Giảm dần vai trò của ngân hàng, chi nhánh tài chính.

Sự lớn mạnh của Fintech có thể là thách thức không nhỏ của ngành dịch vụ tài chính. Việc cạnh tranh thông qua mở rộng mạng lưới các chi nhánh sẽ dần chấm dứt, do chi phí hoạt động cao. Thay vào đó, cạnh tranh công nghệ tài chính hiện đại cũng trở nên gay gắt hơn trong các định chế tài chính. Các ngân hàng hoàn toàn đứng ngoài cuộc trong dịch vụ tiền ảo Bitcoin, công nghệ có thể thay thế cho nhân viên của các ngân hàng, tổ chức tài chính, công ty chứng khoán, bảo hiểm làm việc mà không biết mệt mỏi.

Cuộc chiến thị phần.

Thị phần của các ngân hàng nói chung và các định chế tài chính nói riêng có xu hướng giảm bớt, 'chia phần' cho các công ty Fintech. Các ngân hàng, công ty môi giới chứng khoán,... khi mới bắt đầu xây dựng luật quản lý thì các công ty công nghệ tài chính đang có một lợi thế lớn trong cuộc đua giành thị phần.

\section{Một số khuyến nghị}

Để hệ sinh thái Fintech đem lại nhiều lợi ích hơn nữa cho hoạt động của ngành tài chính - ngân hàng Việt Nam, trong thời gian tới cần trú trọng một số vấn đề sau:

Thứ nhất, Ngân hàng nhà nước cần sớm ban hành khung pháp lý để tạo môi trường cho sự phát triển của FinTech. Việt Nam đang có gần 100 doanh nghiệp FinTech nhưng chỉ khoảng 24 trong đó được Ngân hàng Nhà nước cấp phép ở lĩnh vực thanh toán và chủ yếu hoạt động theo phương thức phối hợp với ngân hàng để cùng cung cấp dịch vụ. Những FinTech ở mảng khác như gọi vốn, quản lý tài sản, cho vay, xếp hạng tín dụng, bảo hiểm, blockchain,... đang hoạt động chủ yếu dựa trên những quy định căn bản từ Luật doanh nghiệp và Luật dân sự, đồng thời phải đối mặt với rất nhiều hoạt động chưa được pháp luật quy định.FinTech gắn liền với khá nhiều rủi ro như bảo mật cá nhân, bảo vệ khách hàng, tín dụng, an toàn mạng, phụ thuộc cồng nghệ, rửa tiền,... Do vậy các quy định pháp lý một mặt phải tách bạch để tạo không gian cho doanh nghiệp Fintech phát triển, mặt khác phải hạn chế được những rủi ro đi kèm.

Xây dựng khung pháp lý thử nghiệm (regulatory sandbox) - cơ chế cho phép các công ty Fintech startup được thí điểm/ thử nghiệm các sản phẩm, dịch vụ trước khi cung ứng sản phẩm chính thức ra thị trường. Sau khi hoàn thành thử nghiệm, xây dựng một khung pháp lý hoàn chỉnh đối với Fintech bao trùm các hoạt động dịch vụ Fintech, bảo vệ người tiêu dùng, phòng chống rửa tiền,...

Thứ hai, cần xây dựng chính sách phát triển FinTech gắn với phát triển hệ thống tài chính ngân hàng và nền kinh tế. Coi sự phát triểncủa FinTec gắn liền với đẩy mạnh ứng dụng khoa học và công nghệ vào lĩnh vực tài chính - ngân hàng, là một bộ phận của ngành tài chính - ngân hàng, chịu sự quản lý của ngành nghề đặc thù. Trên cơ sở đó, tăng cường hợp tác giữa các bên trong việc cung ứng sản phẩm FinTech, tạo điều kiện cho phát triển FinTech ở Việt Nam trong thời gian tới.

Thứ ba, thúc đẩy nghiên cứu và ưng dụng công nghệ blockchain, công nghệ sổ cái phân tán... để nhanh chóng áp dụng trong lĩnh vực tài chính ngân hàng và các lĩnh vực khác do những lợi ích từ côngnghệ này là rất lớn. Song song với yếu tố công nghệ, cần nâng cao trình độ nguồn nhân lực phục vụ việc nắm bắt và quản lý công nghệ FinTech. Có cơ chế khuyến khích đào tạo và thu hút nguồn nhân lực chất lượng cao cho phát triển FinTech. Đồng thời, tranh thủ sự hỗ trợ kỹ thuật và tư vấn của các tổ chức quốc tế như ADB, WBG... và hợp tác song phương với các cơ quan quản lý các nước để trao đổi, chia sẻ kinh nghiệm hữu ích trong quản lý các doanh nghiệp FinTech.

Thứ tư, cần đa dạng hóa sản phẩm và phổ cập kiến thức về FinTech đến người tiêu dùng. Trên cơ sở phát triển sản phẩm FinTech (chủ yếu là thanh toán và chuyển tiền), cần mở rộng các sản phẩm tiềm năng khác như quản lý tài chính, cho vay, tiết kiệm,...nhằm đáp ứng nhu cầu đa dạng của khách hàng. Đồng thời, tích cực quảng bá, phổ cập kiến thức cho người dân về FinTech, cũng như trang bị những thông tin cần thiết nhằm hạn chế rủi ro trong giao dịch FinTech, từ đó giúp nhận biết những lợi ích mà FinTech mang lại.

\section{Những đóng góp của tác giả}

Phạm Thu Hương: Khái niệm và các thành phần, sản phẩm của FinTech; Thu thập số liệu về thị trường Fintech tại Việt Nam; Đề xuất các khuyến nghị; Đánh giá và chỉnh sửa.

Đào Anh Tuấn: Thu thập, phân tích các sản phẩm và mô hình của FinTech; Phân tích các tác 
động của của Fintech tới hoạt động tài chính ngân hàng; Viết bản thảo bài báo.

\section{Tài liệu tham khảo}

Anjan V., (2020). Fintech and banking: What do we know?. Journal of Financial Intermediation, 41 (2020) 100833. https:/ / doi.org/ 10.1016/j.jfi.2019.100833.

Lee, I., \& Shin, Y. J. (2018). Fintech: Ecosystem, business models, investment decisions, and challenges. Business Horizons, 61(1), 35-46. https:/ / doi.org/ 10.1016/j.bushor.2017.09.003.

Milian, Eduardo Z, Mauro de M. Spinola, and Marly M. de Carvalho (2019). "Fintechs: A literature review and research agenda." Electronic Commerce Research and Applications 34100833. https:/ / doi.org/ 10.1016/ j.elerap.2019.100833.
Nguyễn Trung Anh, (2019). Hệ sinh thái Fintech tai Việt Nam. Tạp chí ngân hàng, số chuyên đề Tin học Ngân hàng số 5/ 2019 , tr 32-34.

Phạm Xuân Hòe, (2019). Toàn cảnh Fintech Việt Nam 2019. Tạp chí Thị trưòng Tài chính Tiền tê số 22/ 2019, 25-30.

Solidiance.com, Unlocking Vietnam's Fintech Growth Potential, May 2018. https:/ / www.solidiance.com/ insights/ others/ white-papers/ unlocking-vietnams-fintechgrowth-potential.

United Overseas Bank, Singapore FinTech Association, (2019). FinTech in ASEAN: From Start-up to Scale-up, November 2019. https:/ / www.uobgroup.com/ techecosystem/n ews-insights-fintech-in-asean-2019.html. 